\title{
DISCUSSION
}

\section{Non-uniqueness of flow liquefaction line for loose sand}

\author{
YANG, J. (2002). Géotechnique 52, No. 10, 757-760
}

\section{Jefferies and K. Been, Golder Associates, Vancouver and Houston}

A relationship is proposed for the stress ratio $\eta_{\mathrm{L}}$ at which flow liquefaction instability may arise with loose sand in terms of the sand's state parameter. The usage of the state parameter is in terms of the initial sample void ratio and initial stress state. Formally writing $\psi_{0}$, where the subscript ' 0 ' clarifies definition using initial values, the author proposes that:

$$
\eta_{\mathrm{L}}=\frac{M}{B} \exp \left(A \psi_{0}\right)
$$

where $B$ is a soil property with a common value of $1 \cdot 25(=1 / 0 \cdot 8)$ in the case of Leighton Buzzard and Toyoura sand.

Theoretical interest centres on the appearance of $B$ in equation (3). For a not so loose sand with $\psi_{0}=0$, equation (3) implies that soil deforms plastically and indefinitely at a significantly lower shear stress than that corresponding to critical conditions for any $B>1$. To the discusser's knowledge, equation (3) is the first proposal of a non-unique stress state for critical yielding. Although the idea of nonunique critical void ratios has arisen in the literature, $M$ in triaxial compression has always been treated as unique for any sand.

An alternative to this new view of critical stress conditions is that $B$ has arisen because of the difference between $\psi$ and $\psi_{0}$. The state parameter $\psi$ is a general measure, and its application in constitutive models is as a variable, not an initial index parameter (e.g. Jefferies, 1993; Wood et al., 1994; Manzari \& Dafalias, 1997; Li \& Dafalias, 2000). For undrained tests, the difference between $\psi$ and $\psi_{0}$ arises only through changes in stress. Assuming the usual semi-log representation of the CSL with slope $\lambda$, the two measures are related by

$$
\psi=\psi_{0}+\lambda \log \left(p^{\prime} / p_{0}^{\prime}\right)
$$

Figure 8 shows equation (4) applied to the Leighton Buzzard and Toyoura sand data in the note using previously

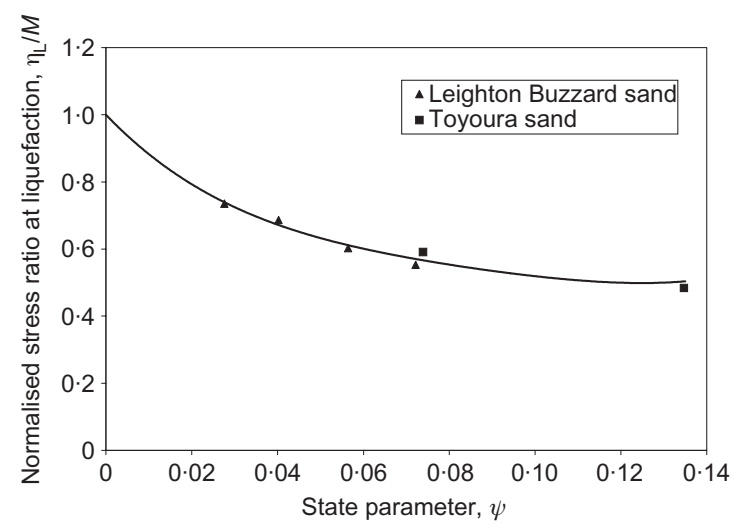

Fig. 8. Stress ratio at peak undrained strength of loose sand expressed in terms of current state parameter $\psi$ at onset of liquefaction published values of $\lambda$, plotting the ratio $\eta_{\mathrm{L}} / M$ to normalise the data. A trend line has been drawn and extrapolated back to $\eta_{\mathrm{L}} / M=1$ for the condition $\psi=0$. This trend line is a plausible fit to the data and preserves a unique critical state. Although a single trend fits Leighton Buzzard and Toyoura sands, these are predominantly quartz soils and rather similar. Fig. 9 shows data for a wider range of sands, and supports the form of the trend drawn through the author's data in Fig. 8, although differences from sand to sand now become apparent.

Also shown in Fig. 9 is a trend line from extrapolating limiting stress ratios in drained triaxial tests on dense sand. Been \& Jefferies (1985) reported a near-unique relationship between $\phi_{\max }$ and $\psi_{0}$. These data can be transformed to a limiting stress ratio, $\eta_{\max }$, at $\psi$. Extrapolating the average trend for $\eta_{\max }$ at $\psi$ from the $\psi \ll 0$ regime of the dense tests, by recognising that $\eta_{\max }$ and $\eta_{\mathrm{L}}$ are similar in concept, gives the line shown in Fig. 9. This dense drained limiting stress ratio sensibly bounds the stress ratios at the onset of liquefaction, although the differences between the loose sand data and the extrapolated limiting ratio from dense tests may be practically significant. An updated form of equation (3) would be useful, respecting the condition that

$$
\psi=0 \Rightarrow \eta_{\mathrm{L}} /=1
$$

A difficulty in representing peak $s_{\mathrm{u}}$ data at onset of liquefaction as a ratio, $\eta_{L}$, is that the pore pressure is changing rapidly at peak $s_{\mathrm{u}}$, and an accurate determination of $p^{\prime}$ is problematic. There are issues of transducer time lag with load-controlled tests, and strain-controlled tests have increased excess pore water pressures from sample creep (Leong et al., 2000). These factors suggest caution in relying on $\eta_{L}$, and perhaps an undrained strength ratio $\left(s_{\mathrm{u}} / \mathrm{p}_{0}^{\prime}\right)$ approach following Bishop (1971) is more appropriate in practice.

\section{Author's reply}

The author thanks the discussers for their interest in the topic and their valuable comments. They offer an alternative interpretation that uses the state parameter at peak strength rather than the initial state parameter $\psi_{0}$ used in the author's proposal. In general the trend shown in Fig. 8 is quite similar to that presented in terms of $\psi_{0}$, and it is of particular interest to notice that the data shown in Fig. 9 for a wider range of sands support the form of the trend. In what follows, the author would like to clarify several points.

(a) The critical state line (CSL) is usually represented by a linear relationship in a semi-log form. This representation makes it convenient to relate the state parameter $\psi$ as a variable with its initial value. Some experimental results have, however, indicated that the CSL for sands is not a straight but a curved line on the semi-log scale (e.g. Verdugo \& Ishihara, 1996). For this reason, caution should be exerted when using the linear relationship equation (4) to locate the values of $\psi$ at specific states. Alternative representations of the CSL on a different scale may need to be made to fit the experimental data better. 


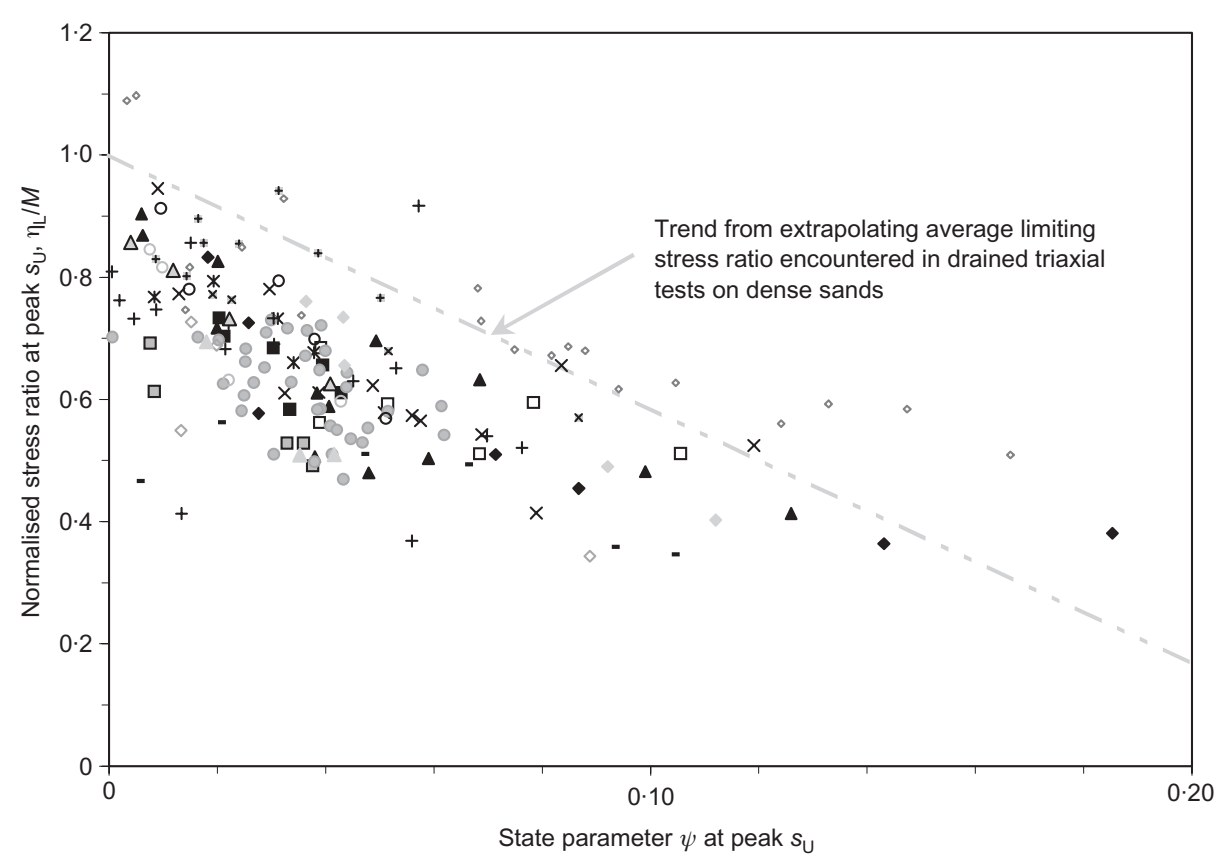

- Oil Sands Tails

- Amauligak 165

ㅁ Erksak 3201/1,2

ㅁ Erksak 355/3

- Erksak 330/0.7

$\times$ Isserk 210/2,5,10

* Isserk 230/1

- Alaskan BS 140/5,10

- Banding Sands

+ Castro Sand B

+ Castro Sand C

$\times$ Hilton Mines

- Hokksund

- Monterey \#0

$\diamond$ Ottowa

Reid Bedford

$\Delta$ Ticino 5430/0

Toyoura Sands

$\Delta$ Nerlerk 270/1

- Kogyuk 350/0,2,5,10

State parameter $\psi$ at peak $s_{U}$

Fig. 9. General trend in stress ratio at peak strength undrained strength for sands

(b) The state parameter is a measure of how far the material state is from the critical state in terms of density. Its advantage has been recognised by its application in constitutive modelling of sand behaviour. From the point of view of constitutive modelling, the state parameter $\psi$ is an internal variable that can be incorporated in the formulation, as correctly pointed out by the discussers. To illustrate the role of state parameter in such applications, Fig. 10 shows the evolution of the state parameter during the deformation of Toyoura sand subject to undrained triaxial compression, and Fig. 11 presents the relationship between the dilatancy, a key issue in studying the behaviour of sands, and the state parameter as a variable. The responses are obtained within the framework of statedependent modelling ( $\mathrm{Li} \&$ Dafalias, 2000), and the dilatancy is defined as

$$
d=\frac{\mathrm{d} \varepsilon_{\mathrm{v}}^{\mathrm{p}}}{\mathrm{d} \varepsilon_{\mathrm{q}}^{\mathrm{p}}}
$$

the ratio of plastic volumetric strain increment to

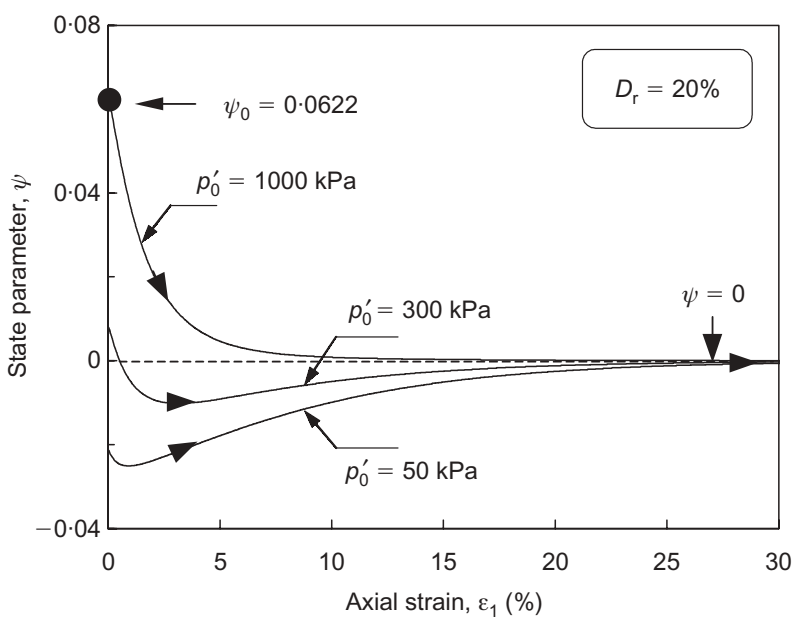

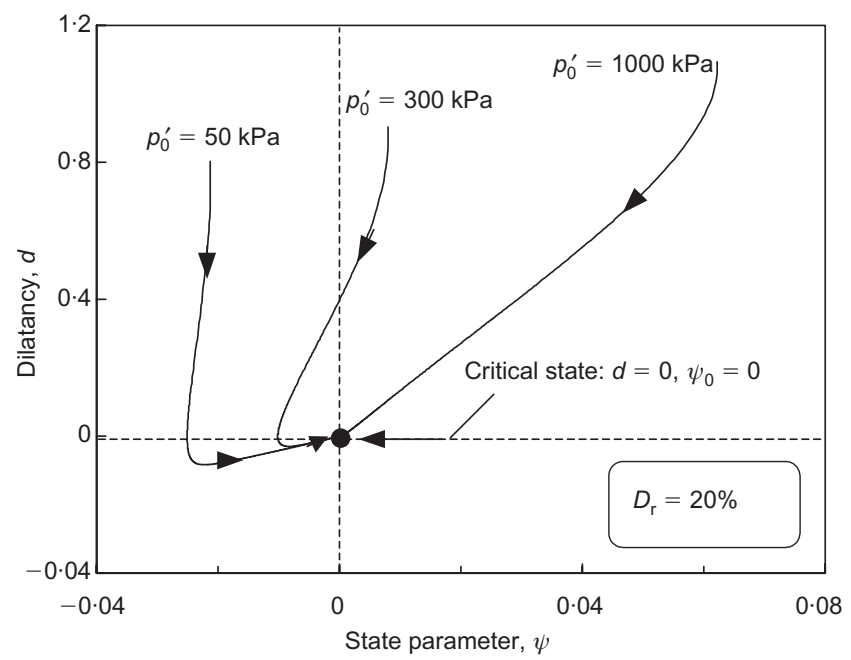

Fig. 11. Relationship between dilatancy and state parameter during the deformation of Toyoura sand subject to undrained triaxial compression

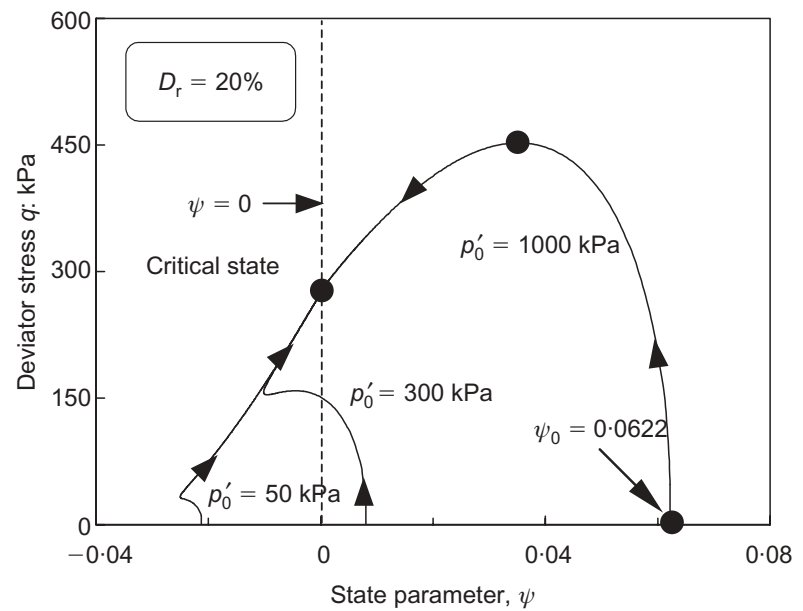

Fig. 10. Evolution of state parameter during deformation of Toyoura sand subject to undrained triaxial compression 
plastic deviator strain increment. It is worthwhile noting that the manner of the evolution of the state parameter with the deviator stress is very similar to that followed by the stress paths in terms of $q$ and $p^{\prime}$.

(c) If it is the case that the state parameter $\psi$ is incorporated in the constitutive formulation as an internal variable, mathematically it is even possible to derive an analytical relationship between the peak strength and the corresponding state parameter, as demonstrated in Yang \& Li (2004), where a unique relationship has been established between the drained peak friction angle, $\phi_{\mathrm{p}}^{\prime}$, and the state parameter at peak, $\psi_{\mathrm{p}}$ (see Fig. 12). In engineering practice it would, however, be difficult to determine $\psi_{\mathrm{p}}$ accurately. As such, the peak friction angle has also been presented in terms of the initial state parameter, $\psi_{0}$, for the purpose of practical applications (Yang \& Li, 2004). The initial

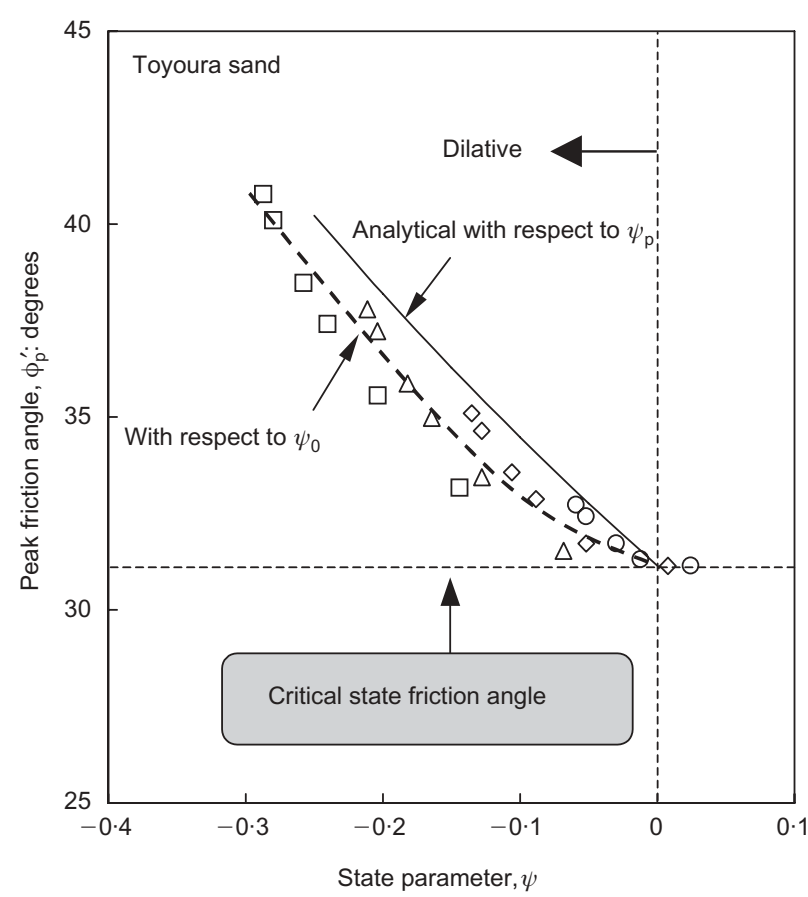

Fig. 12. Relationship between drained peak friction angle and state parameter state parameter describes the material state before the deformation occurs. It is apparent from Fig. 12 that both relationships (indicated by the solid and dashed lines respectively) exhibit a similar trend, although differences exist between them.

(d) Some problems may appear with an accurate determination of the mean effective stress at onset of liquefaction in the laboratory, as remarked by the discussers. It is also noted, on the other hand, that quality test data can be obtained with the development of testing techniques (Verdugo \& Ishihara, 1996; Vaid et al., 2001). The proposed approach has its advantage in that it establishes a relationship for the stress ratio at onset of liquefaction in terms of the initial state parameter, which simultaneously accounts for the initial void ratio and initial stress level, and has been related to some in-situ test results (e.g. CPT resistance). The valuable data provided by the discussers for a wider range of sands also indicate the potential of the approach in practice.

\section{REFERENCES}

Bishop, A. W. (1971). Shear strength parameters for undisturbed and remoulded soil specimens. Stress-strain behaviour of soils: Proceedings of the Roscoe Memorial Symposium (ed. R. H. G. Parry), pp. 3-58. Henley-on-Thames: G.T. Foulis.

Jefferies, M. G. (1993). NorSand: a simple critical state model for sand. Géotechnique 43, No. 1, 91-103.

Leong, W. K., Chu, J. \& Teh, C. I. (2000). Liquefaction and instability of a granular fill material. Geotech. Test. J. 23, No. 2, $178-192$.

Li, X. S. \& Dafalias, Y. F. (2000). Dilatancy for cohesionless soils. Géotechnique 50, No. 4, 449-460.

Manzari, M. T. \& Dafalias, Y. F. (1997). A critical state two-surface plasticity model for sands. Géotechnique 47, No. 2, 255-272.

Vaid, Y. P., Eliadorani, A., Sivathayalan, S. \& Uthayakumar, M. (2001). Laboratory characterization of stress-strain behavior of soils by stress and/or strain path loading. Geotech. Test. J. 24, No. 2, 200-208.

Verdugo, R. \& Ishihara, K. (1996). The steady state of sandy soils. Soils Found. 36, No. 2, 81-91.

Wood, D. M., Belkheir, K. \& Liu, D. F. (1994). Strain softening and state parameter for sand modelling. Géotechnique 44, No. 2, $335-339$.

Yang, J. \& Li, X. S. (2004). State-dependent strength of sands from the perspective of unified modeling. J. Geotech. Geoenviron. Engng, ASCE 130, No. 2 (in press). 